\title{
Double Exposure Vulnerability of Agriculture in Southwest Jamaica
}

\author{
Douglas W. Gamble ${ }^{1}$, Scott Curtis ${ }^{2}$, Jeff Popke ${ }^{2}$ \\ ${ }^{1}$ Department of Earth and Ocean Sciences, UNC Wilmington \\ Wilmington, NC, USA \\ ${ }^{2}$ Department of Geography, Planning \& the Environment, East Carolina University \\ Greenville, NC, USA \\ gambled@uncw.edu
}

\begin{abstract}
This case study describes results of research completed 2013-2015 with the purpose of assessing the vulnerability of small farmers in the face of climate change and economic transformation in St. Elizabeth Parish, Jamaica. In particular, the study focuses upon water as a key factor in creating and overcoming double exposure vulnerability. Results indicate that farmers in the study area have developed a strong ethnoclimatological tradition and are very aware of the local meteorological conditions and their relationship to drought despite the lack of readily available, detailed meteorological data for the region. In general, low rain amounts, low soil moisture, and high wind conditions are the cues farmers associated most directly with drought occurrence. Interviews with stake holders across the study area indicate that Jamaican farmers continuously modify water assemblages to control variability and calculate success. Ultimately, farmers intend to be 'double winners' in calculating favourable hydro-climatic and market conditions that leverage the agency of water for success. These results provide insight that can be used by Jamaica and other Caribbean Small Island Developing States to address increased drought in a future warmer climate.
\end{abstract}

Keywords: double exposure, drought, agriculture, Jamaica

\section{Introduction}

This case study describes results of research completed 2013-2015 with the purpose of assessing the vulnerability of small farmers in the face of climate change and economic transformation in St. Elizabeth Parish, Jamaica (Figure 1). In particular, the study focuses upon water as a key factor in creating and overcoming double exposure vulnerability. Accordingly, this study will answer two primary research questions: 1) what vulnerability do farmers face as a result of double exposure (climate and economic change)?; and 2) what role does water have in the creation of vulnerability or enhancing the resilience of small-scale agriculture in the face of uncertainty and change? These questions were examined in a region with extensive smallholder food production for the domestic market in southwest Jamaica. The project engaged a mixed methods research design to combine analysis of meteorological data with a qualitative investigation of farmer knowledge, perception, and adaptation to changing regional climate and economic conditions.

\section{The Case Study}

A total of fifteen farms were selected to be included in this study to examine the relationships between farm-level water budgets, drought perceptions, and irrigation infrastructure deployed by individual producers. The farms chosen for this study represent the total spectrum of topographic, hydroclimatic, and farm capitalization conditions in the southern portion of St Elizabeth Parish. Meteorological instruments including a tipping bucket rain gauge (rain mm), a soil moisture probe at $10 \mathrm{~cm}$ depth (\% water content), and a temperature sensor (degrees Celsius), were deployed on each farm June 15, 2013. Rainfall was recorded in increments of $0.254 \mathrm{~mm}$ and all other data was collected at 6 hour intervals. After data collection, soil moisture was standardized through transformation of raw data for each time series into a z-score to allow for across site comparison ((observation-mean)/standard deviation), a common technique used to standardize data in climatology (Wu et al., 2001; Dogan et al., 2012; Jain et al., 2015).

All fifteen farmers were telephoned by the project manager (residence in Kingston, Jamaica) every two weeks to document farm activities and perception of drought from June 2013 to May 2015. Thirteen times the project manager could 
not reach a particular farmer, so the final number of phone-surveys was 677. To the question of drought, farmers were given the choice of three responses: yes drought, no drought, or uncertain of drought. The observed soil moisture, temperature,

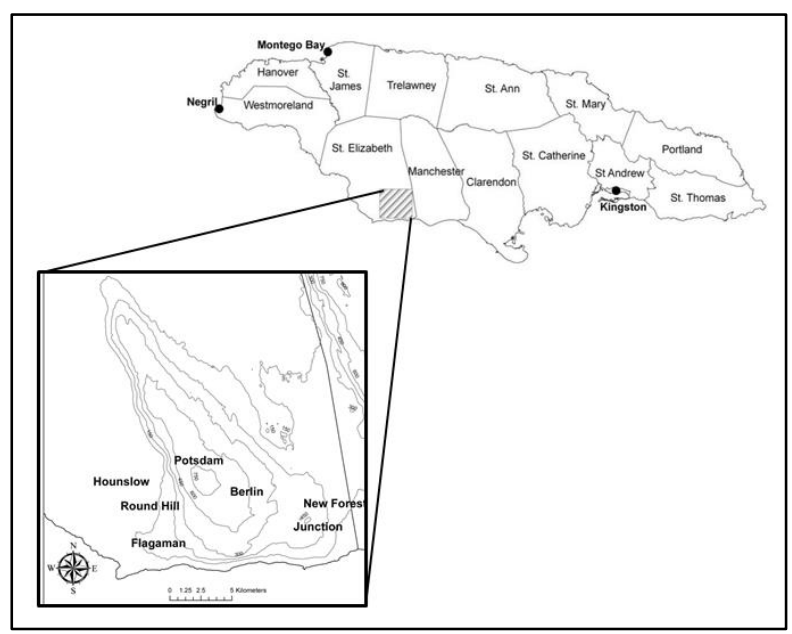

Fig. 1: Map indicating location of study area in Jamaica (hashed area), elevation, and communities within the study area.

and rainfall data were aggregated to match corresponding farm survey data at the two-week interval for a total of 46 biweekly increments. Whereas minor data gaps occurred in the phone survey data, gaps occurred in the hydro-climatic data more frequently due to instrument failure. Across all farms, a total of 392 phone survey time periods out of a possible 677 (58\%) had the full complement of hydro-climatic data. All statistical analysis was completed with the 392 two-week data set.

Beyond the phone surveys, farmers, higglers and other purchasers of produce, purveyors of water, and retail farm supply stores were interviewed during the summers of 2013-2015 to document their agricultural practices and any significant challenges, concerns, or sources of stress that they perceive over the course of the growing season. The aim of interviews was to capture the range of different perspectives and experiences among farmers in the case study area. Interviews lasted 45-75 minutes, and consisted of a brief survey to collect standard summary data on farm characteristics, followed by a more extended, semi-structured conversation format. A total of 78 interviews were completed encompassing 55 recorded hours of conversations which were then transcribed for analysis.

Analysis was first conducted with meteorological data aggregated for the study area to provide insight into a general conceptual model of farmer drought perception in southern St Elizabeth Parish. Secondly, analysis was conducted with individual farm level meteorological data to identify how such a general conceptual model may vary between individual farm sites. Once the physical dimensions of drought were established for the study area, interviews were reviewed to find additional information to identify ways in which the community experienced and reacted to drought. Through such an analysis we documented the role water has in the creation of vulnerability or enhancing the resilience of small-scale agriculture in the face of uncertainty and change in a drier future climate.

Farmer phone surveys indicate that the overall responses to the question of "Did you experience drought in the past two weeks?" was 225 yes, 129 no, and 38 uncertain; indicating that farmers perceived their farms to be under drought stress over half (57\%) of the two-week periods June 2013 May 2015. A mapping of the frequency of farmer drought perception suggests a strong relationship between drought perception and farm elevation (Figure 2). The range in elevation across the study area is significant (0-800 meters), with this full range represented by the case study farms (elevation range 13-794 meters). Farms with the highest frequency of drought identification are clustered at lower elevations. A Pearson correlation analysis of farm elevation and percent frequency of drought perception indicates a strong, statistically significant (95\% confuidence) negative association between the frequency that farmers perceive and reported droughts in their phone surveys and elevation $(r=-0.64)$. This is likely due to generally lower temperatures and higher precipitation totals at the higher elevation of the Santa Cruz Mountains, which create hydroclimatic conditions less conducive to drought development. Soil moisture does not appear to be dependent on elevation as indicated by a Pearson correlation of farm 
elevation and mean farm soil moisture values $(r=0.22)$. This result suggests that soil moisture conditions are driven more by farm site, situation, and management as opposed to overall topography and associated microclimates.

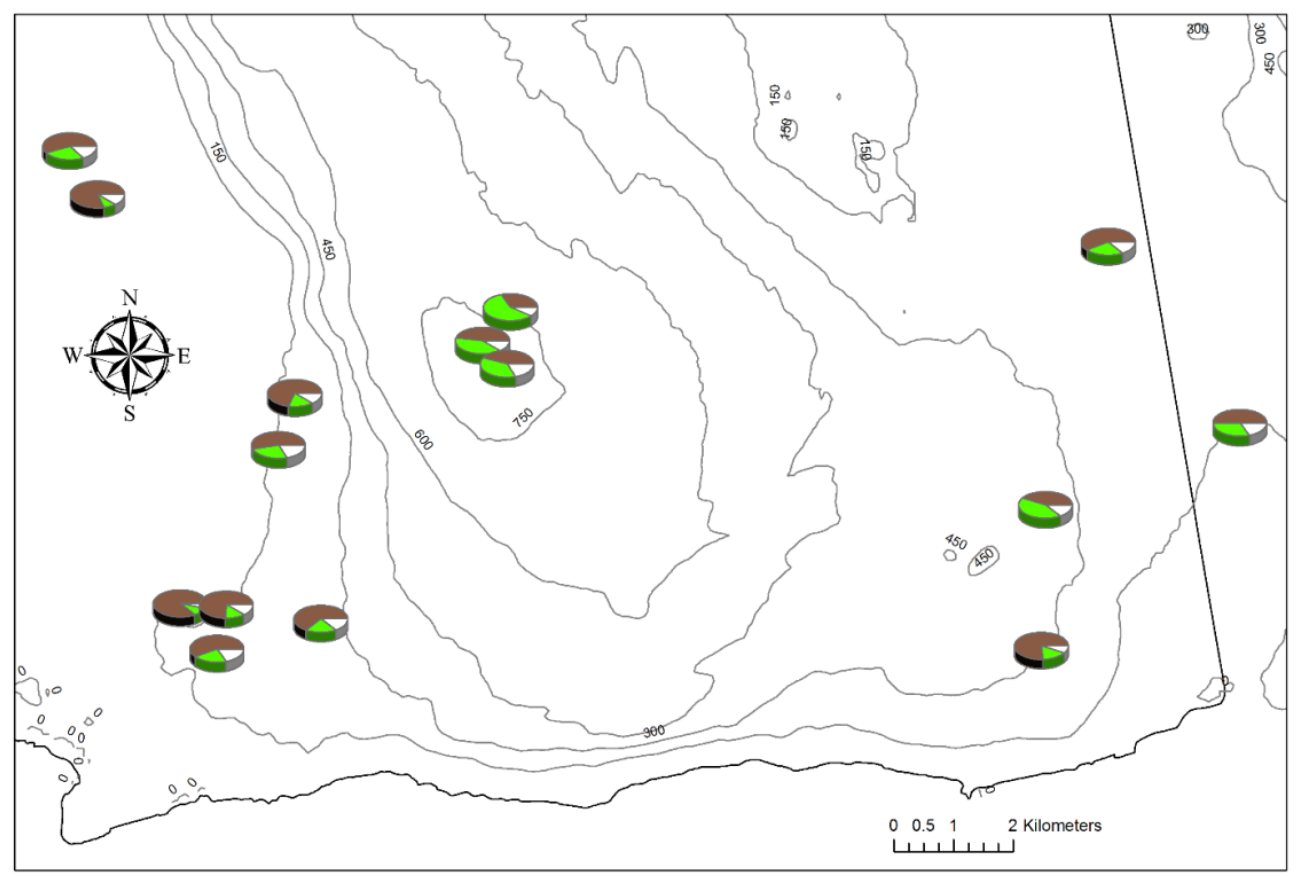

Fig. 2: Southern St Elizabeth Parish case study farm location, elevation, and the frequency of survey drought classes: yes drought (brown), no drought (green) and uncertain of drought (white).

Next precipitation, temperature and soil moisture were averaged across the study area for each of the 46 bi-weekly increments. In $43 \%$ of the phone surveys, farmers also indicated that wind was an important environmental stressor, particularly in terms of desiccating fields. Thus, occurrence of high winds was added to the analysis. In regard to strength of association between meteorological variables and drought perception, results are consistent with the typical meteorological

framework of drought; low precipitation, dry soil, and high winds. Pearson correlation analysis (statistically significant with $95 \%$ confidence) indicates perception of drought is negatively correlated with rainfall and soil moisture ( $\mathrm{r}=$ $-0.62 \&-0.63$ respectively) and positively with perception of high winds $(\mathrm{r}=+0.66)$. Wind is also related to perception of drought at a two-week lag $(\mathrm{r}=0.58)$. This lag indicates that farmers recognize that drought can be created by cumulative wind conditions and their desiccating effect. Such a lag is not uncommon in drought perception due to it being a slowly developing phenomenon that does not have a discrete beginning or ending point, and most people do not notice or react to drought conditions until they are in the middle of a water shortage and faced with its greatest impact (Wilhite, 2000).

Comparison of the frequency of farm level drought perception categories by season indicates that only during the fall were non-drought conditions perceived more often than drought conditions, while the rest of the year, farmers' perceived drought to non-drought at a ratio of at least 2:1 (Table 1). A Mann-Whitney U test indicates that in Spring and Fall, all three meteorological variables are significantly different for the yes-drought and no-drought categories; indicating less rain, high temperatures and low soil moisture are associated with droughts. In the summer, rain and soil is significantly different for drought classes but temperature is not and in winter only temperature is significantly different between drought categories.

Previous research has documented that farmers in the study area made statements in interviews that year-to-year comparisons of seasonal rains are an important factor in farmers' perceptions of drought within St Elizabeth Parish (Gamble et al. 2010; Popke et al., 2014) and our interviews with farmers summer 2013 - 2015 indicate they still believe that this variability is occurring. To further test this frequent farmer claim, all two-week periods' rainfall and soil moisture in the study period were compared to the rainfall or soil moisture of the same two-week period in the preceding year to determine if the current year was wetter or drier. Specifically, this comparison took the form of mean rainfall (soil 
moisture) June 15-30, 2013 subtracted from June 15-30, 2014, then July 1-15, 2013 subtracted from July 1-15, 2014, continued through time series to May 1-15, 2014 subtracted from May 1-15, 2015. A negative difference between the two periods indicates the current year was drier than the preceding year for that two-week period, while a positive difference indicates the current year was wetter than the preceding year for that two-week period. A one-way analysis of variance (ANOVA) was completed to determine if the difference values in mean rainfall and soil moisture for the coupled two week periods were significantly different between the three farmer drought perception categories: uncertain, yes, no. The ANOVA indicates that the differences in the mean rainfall and soil moisture of the three types are statistically significant ( $p<0.001$ rainfall and $p=0.001$ soil moisture) (Table 2 and 3). Since the mean values are negative in the yes drought category and positive in the no drought category, it can be inferred that farmers identify drought by comparing the current year to the previous year and if it is drier in the current year, a drought is identified. The uncertain drought perception difference value is close to zero suggesting that with no difference between years, farmers are uncertain of drought conditions. It is more difficult to interpret the high positive difference in mean soil moisture conditions in the uncertain drought category. Perhaps this is best explained by farmers applying water to fields, creating wet farm conditions during overall drought conditions; the contradictory information causing uncertainty.

Table 1: Seasonal frequency of yes and no drought classes and results of the Mann-Whitney U test comparing meteorological variable by season.

\begin{tabular}{|c|c|c|c|c|c|c|c|c|}
\hline \multirow{3}{*}{$\begin{array}{l}\text { Frequency of } \\
\text { survey drought } \\
\text { classes }\end{array}$} & \multicolumn{2}{|c|}{ DJF - median } & \multicolumn{2}{|c|}{ MAM - median } & \multicolumn{2}{|c|}{ JJA - median } & \multicolumn{2}{|c|}{ SON - median } \\
\hline & & $\mathrm{n}=52$ & Yes & $n=60$ & & $\mathrm{n}=81$ & Yes & $\mathrm{n}=32$ \\
\hline & No & $\mathrm{n}=28$ & No & $n=23$ & No & $\mathrm{n}=28$ & No & $\mathrm{n}=50$ \\
\hline \multirow{3}{*}{ Rain (mm) } & Yes & 25.3 & Yes & 26.4 & Yes & 10.2 & Yes & 24.3 \\
\hline & No & 27.7 & No & 48.5 & No & 78.1 & No & 70.4 \\
\hline & $p$-value & .815 & p-value & .000 & $\mathrm{p}$-value & .000 & $\mathrm{p}$-value & .042 \\
\hline \multirow{3}{*}{ Temp $\left({ }^{\circ} \mathrm{C}\right)$} & Yes & 25.5 & Yes & 27.0 & Yes & 28.4 & Yes & 27.6 \\
\hline & No & 24.6 & No & 25.3 & No & 27.7 & No & 26.6 \\
\hline & p-value & .035 & p-value & .004 & p-value & .139 & $\mathrm{p}$-value & .013 \\
\hline \multirow{3}{*}{ Soil } & & +0.48 & Yes & +0.01 & Yes & -0.91 & Yes & +0.04 \\
\hline & No & +0.35 & No & +0.42 & No & -0.26 & No & +0.52 \\
\hline & $p$-value & .482 & p-value & .042 & p-value & .014 & $\mathrm{p}$-value & .013 \\
\hline
\end{tabular}

Table 2: Difference in current year and previous year mean two-week rainfall (mm) in Southern St Elizabeth, Jamaica June 15 , 2013 to May 15, 2015.

\begin{tabular}{|l|c|c|c|}
\hline Drought Category & Uncertain & Yes Drought & No Drought \\
\hline $\begin{array}{l}\text { Mean Difference in } \\
\text { Current and Previous } \\
\begin{array}{l}\text { Two-week Rainfall } \\
(\mathrm{mm})\end{array}\end{array}$ & -0.5 & -29.4 & 33.6 \\
\hline Category Frequency & & & \\
\hline
\end{tabular}

Table 3: Difference in current year and previous year mean two-week soil moisture (z-score) in Southern St Elizabeth, Jamaica June 15, 2013 to May 15, 2015.

\begin{tabular}{|l|c|c|c|}
\hline Drought Category & Uncertain & Yes Drought & No Drought \\
\hline $\begin{array}{l}\text { Mean Difference in } \\
\text { Current and Previous } \\
\text { Two-week Soil } \\
\text { Moisture (z-score) }\end{array}$ & 0.431 & -0.303 & 0.206 \\
\hline Category Frequency & & & \\
\hline
\end{tabular}


In order to assess if the existence of a farm irrigation system has an impact on farmer drought perception, a t-test of the frequency of drought perception for irrigated versus non-irrigated farms was completed. The test indicates there is no significant difference $(\mathrm{p}=0.356)$ in drought perception between irrigated and non-irrigated farms. Such a result suggests that farmers perceive drought through the existing micro-climate (rain and wind conditions) in which the farm operates as opposed to farm specific soil moisture conditions. Thus, irrigation is viewed as more of a tool to respond or adapt to drought as opposed to avoid or mitigate drought. This is further supported by a plot of 6-hourly soil moisture at an irrigated and non-irrigated farm with the same elevation in the Hounslow community March to September 2014 (Figure 3). Southern St. Elizabeth Parish, Jamaica experienced an extreme spring/summer drought event in 2014, characterized by reduced rainfall, high temperatures, and strong winds. The mean precipitation recorded by study farm rain gauges $(56 \mathrm{~mm}$ in April 2014, $90 \mathrm{~mm}$ May 2014, $9 \mathrm{~mm}$ June 2014, and $22 \mathrm{~mm}$ July 2014) was well below the 30-year mean for the area. Total rainfall April-July 2014 was 50\% of the 30-year mean with June rainfall less than $10 \%$ of the 30 -year mean. All farmers in the study perceived drought throughout this time period. However, Figure 3 illustrates that despite the perception of drought, it is clear that the irrigated farm had much higher soil moisture values. Thus, elevation, the greatest control on micro-climate in the study area, appears to have a greater impact on farmer perception of drought than existence of an irrigation scheme on a given farm. As seen in Figure 4, irrigation systems exist across a range of elevations and do not influence the overall pattern of higher elevations having a lower frequency of perceived drought and lower elevations having a higher frequency of perceived drought.

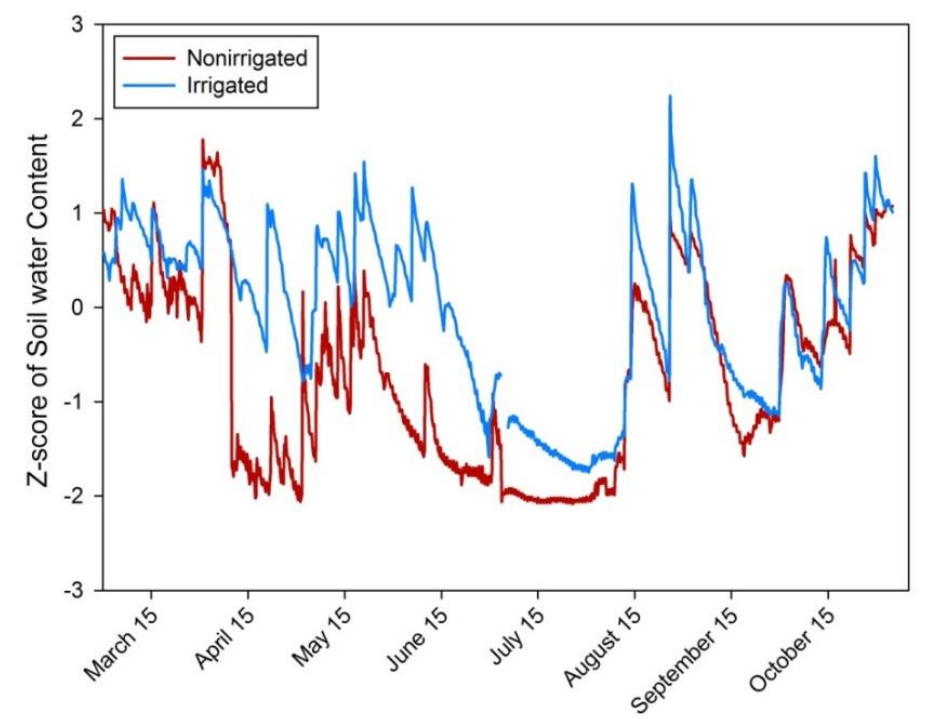

Fig. 3: Six-hourly soil moisture z-score for the 2014 drought in Hounslow, St Elizabeth: irrigated versus non-irrigated farm.

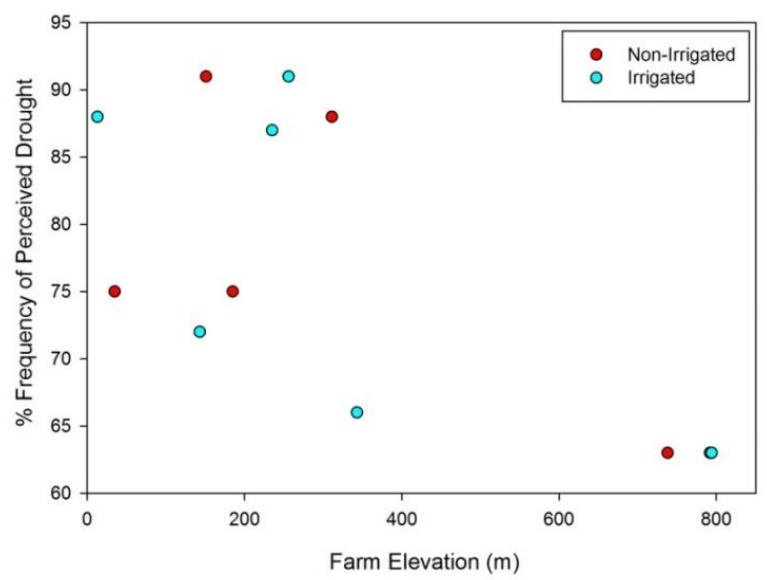

Fig. 4: Farm elevation and percent frequency of perceived two*week drought March-October 2014 southern St, Elizabeth Parish, Jamaica. 
The interviews completed in southern Saint Elizabeth Parish 2013-2015 provided additional information which augments the data collected on the 15 farms and in the phone surveys. Farmers indicated the greatest stresses to agricultural productivity in Jamaica are: 1) unpredictable nature of rain/access to water (particularly increased variability of April-May rains); 2) harvested crop price instability; 3) occurrence of pest/disease; 4) finding a market for products; 5) increased cost and decreased quality of seed, fertilizer, and pesticides; 6) increased competition from imported food; and 7) decreasing quality of soil. These seven components are the basic components to double exposure vulnerability in the region. Farmers respond to these stressors through a broad spectrum of ad-hoc water assemblages that are designed to shape water access and use. These assemblages represent a combination of local micro-climate, material, knowledge, strategies and risk tolerance, financial capital, and networks of social capital. An example of a low cost/capital water assemblage consists of a farmer placing guinea grass mulch over fields to reduce evapotranspiration and place a series of rain water barrels in fields to collect rain water. The rain water is them used for hand watering as needed. An example of a high cost/capital water assemblage is a farm which has gravity feed drip irrigation with water stored in large tanks. Once the storage tanks become close to empty, the farmer will drive his water truck to a community well, fill it, and then bring the water back and unload it into the water storage tanks to continue irrigation.

These water assemblages are not static but rather fluid, constantly being reconfigured to leverage the ever-changing material and capital available to each farmer. For instance, a farmer might have sufficient water due to access to an irrigation-well. However, if the pump that extracts water from the well burns out, he must revert to a more vulnerable water assemblage of rain barrels and hand watering until he can replace the pump. Another example is when a friend, who is going off island, lends his water truck to another farmer with no truck for the early season; allowing for a temporary short term water assemblage with lower vulnerability. These assemblages should not be characterized by access to capital alone. Local marketing and distribution structures play an important role in these assemblages. Many farmers use game theory to profit off gluts or 'catch a crop'; selling a crop at the peak price during a natural hazard such as drought due to decreased supply in the region. Thus, through use of this strategy, farmers transform double exposure vulnerability into an opportunity as opposed to a risk.

Government initiatives to lessen double exposure vulnerability of farmers are also part of these water assemblages. The government response has been focused upon supporting the development of modern and technologically sophisticated agribusiness, in particular development of greenhouse farming. However, such high capital farming has been used by a limited number of farmers in southern St. Elizabeth due to the considerably high investment requirement in terms of both financial and social capital, and thus has limited impact on the majority of farmers in the area.

\section{Discussion}

A detailed analysis of 15 farms in St Elizabeth Parish 2013-2015 indicates that drought perception is not evenly distributed across space and time in southern St Elizabeth Parish. In terms of spatial distribution, drought perception is more frequent at lower elevations, underscoring the importance of the variety of micro-climates (low elevation with low precipitation and higher temperatures and vice versa at higher elevations) within the study area. In terms of the annual seasonal cycle, drought is perceived more than twice as often as non-drought by farmers during winter, spring, and summer. While in contrast, non-drought conditions are perceived twice as much as drought conditions in fall.

The farmers of southern St Elizabeth have developed a strong ethnoclimatological tradition and are very aware of the local meteorological conditions and their relationship to drought despite the lack of readily available, detailed meteorological data for the region. In general, low rain amounts, low soil moisture, and high wind conditions are the cues farmers associated most directly with drought occurrence. A comparison of current moisture conditions to moisture conditions one-year prior is also an important factor in farmer identification of drought. The existence of irrigation on a farm does not appear to impact farmer perception of drought. Irrigation in the study area can be characterized as a tool for drought response or adaption as opposed to a tool for drought mitigation.

Interviews with stake holders across the study area indicate that Jamaican farmers continuously modify water assemblages to control variability and calculate success. Ultimately, farmers intend to be 'double winners' in calculating favourable hydro-climatic and market conditions that leverage the agency of water for success. The continual modification of an assemblage is essential due to increasing variability of the hydro-climate conditions, and the increasing variability and complexity of market dynamics in Jamaica. Ultimately farmers attempt to calculate greater control over their water assemblage to guarantee success. 
The region as a whole can be thought of as a mosaic of exposure assemblages as opposed to separate exposure units. Further, the continual modification of these assemblages can be viewed as a constant process as opposed to a specific response to a stress or shock which results in a "before and after" condition on a farm. The result is that the level of a farm or community's double exposure is not constant over time, rather it changes through constant evolution and reconfiguration of existing assemblages. In many situations, double exposure ends up not being additive; combining negative exposures to create double 'losers', or positive exposures to create double 'winners'. Rather, farmers are trying to redistribute the agency of water through addressing a hydro-climatic or market component of an assemblage to create a level of acceptable exposure. Each farmer calculates the level of acceptable exposure and redistributes capital and effort cross their assemblage to reach this level; a constant balancing or budgeting act to redirect the flow of the agency of water.

The majority of calculations that attempt to modify assemblages to capture the agency of water involve expenditure of capital (social, technology and financial). However, one unique and unexpected calculation utilized in Jamaica is to 'catch a crop' or harvest a crop at the peak price during a climatic shock (drought or hurricane). Through such a calculation, the farmers are trying to leverage a 'random' process which negates any advantages or control in assemblages of competing farmers.

\section{Conclusions}

These results provide insight that can be used by Jamaica and other Caribbean Small Island Developing States to address increased drought in a warmer environment. First, farmers are very aware of local meteorological conditions and have a strong collective ethnoclimatology of the region and efforts to address drought should focus on providing information that augments this knowledge and creates farmer centred monitoring and forecasting tools. Second, many Caribbean islands have a high degree of variability in topography and microclimates. Drought response and mitigation planning should be aware of such variability and that perception of drought can vary from each microclimate. Flexibility in addressing a variety of drought types on Caribbean islands is essential. Thirdly, year-to-year meteorological variability is very important to farmer perception of drought. Any monitoring or forecasting efforts which attempts to link in current to previous year moisture conditions will be well received by farmers. Lastly, climate change policy needs to allow for farmers to have maximum flexibility in modifying their water assemblages to reduce double exposure vulnerability. Without such flexibility, the number of options through which farmers can capitalize on to redistribute his or her vulnerability may be limited and in turn, farmers will be less resilient to climate change.

\section{Acknowledgements}

This material is based on work supported by the U.S. National Science Foundation under Grant No. BCS1229897/1229900. We gratefully acknowledge the willingness and enthusiasm of the farmers of St. Elizabeth parish for participation in this project.

\section{References}

[1] H. Wu, M. J. Hayes, A. Weiss, and Q. Hu, "An evaluation of the Standardized Precipitation Index, the China zindex, and the statistical z-score," Int. J. Climatol., vol. 21, pp. 745-758, 2001.

[2] S. Dogan, A. Bektay, and V.P. Singh, "Comparison of multi-monthly rainfall-based drought severity indices with application to semi-arid Konya closed basin, Turkey," J. Hydrol., vol. 470-471, pp. 255-268, 2012.

[3] V. K. Jain, R. P. Pandey, M. K. Jain, and H. R. Byun, "Comparison of drought indices for appraisal of drought characteristics in the Ken River basin," Weather and Climate Extremes, vol. 8, pp. 1-11, 2015.

[4] D. A. Wilhite, "Drought as a natural hazard: Concepts and definitions," in Drought: A global assessment, D.A. Wilhite, Ed., London: Routledge, 2011, pp. 1-11.

[5] D. W. Gamble, D. Campbell, T. L. Allen, D. Barker, S. Curtis, D. F. M. McGregor, and J. Popke, "Climate change, drought, and Jamaican agriculture: local knowledge and the climate record," Ann. Assoc. Am. Geogr., vol. 100, no. 4, pp. 880-893, 2010.

[6] J. S. Popke, S. Curtis, and D. W. Gamble, "A social justice framing of climate change discourse and policy: Adaptation, resilience and vulnerability in a Jamaican agricultural landscape," Geoforum, DOI 10.1016/j.geoforum.2014.11.003, 2014. 